\title{
Metabolite Ratio for Maximum Concentration
}

National Cancer Institute

\section{Source}

National Cancer Institute. Metabolite Ratio for Maximum Concentration. NCI Thesaurus.

Code C156569.

The ratio of metabolite maximum concentration to the parent analyte maximum

concentration. 